\title{
Clinical anatomy of the maxillary nerve block in pediatric patients
}

\author{
$\underline{\text { Lané Prigge }}^{1,2}$, Albert-Neels van Schoor ${ }^{1}$, Marius C Bosman ${ }^{1}$, and Adrian T Bosenberg ${ }^{3}$ \\ ${ }^{1}$ Department of Anatomy, School of Medicine, Faculty of Health Sciences, University of Pretoria, Pretoria, South Africa. \\ ${ }^{2}$ Department of Anatomy, School of Pathology and Pre-Clinical Sciences, Faculty of Health Sciences, University of Limpopo \\ (Medunsa Campus), Ga-Rankuwa, South Africa. \\ ${ }^{3}$ Department of Anesthesiology and Pain Management, Faculty of Health Sciences, University of Washington, Seattle, WA, \\ USA.
}

${ }^{*}$ Correspondence to:

Ms. L Prigge

Department of Anatomy, Section of Clinical Anatomy, School of Pathology and Pre-Clinical Sciences, Faculty of Health Sciences, University of Limpopo (Medunsa Campus), Ga-Rankuwa. PO Box 232, Medunsa, 0204

Tel: $+2712.5214313 /+27823817256$

Telefax: +27125214512

E-mail: lane.prigge@ul.ac.za

\section{Abstract}

Anatomical landmarks in children are mostly extrapolated from studies in adults. Despite this, complex regional anesthetic procedures are frequently performed on pediatric patients. Sophisticated imaging techniques are available but the exact position, course and/or relationships of the structures are best understood with appropriate anatomical dissections. Maxillary nerve blocks are being used for peri-operative analgesia after cleft palate repair in infants. However, the best approach for blocking the maxillary nerve in pediatric patients has yet to be established.

In an attempt to define an optimal approach for maxillary nerve block in this age group three approaches were simulated and compared on 10 dried pediatric skulls as well as 30 dissected pediatric cadavers. The needle course, including depth and angles, to block the maxillary nerve, as it exits the skull at the foramen rotundum within the pterygopalatine fossa, was measured and compared. Two groups were studied: Group 1 consisted of skulls and cadavers of neonates (0-28 days after birth) and Group 2 consisted of skulls and cadavers from 28 days to one year after birth.

No statistically significant difference $(p>0.05)$ was found between the left and right side of each skull or cadaver. Only technique B, the suprazygomatic approach from the frontozygomatic 
angle towards the pterygopalatine fossa, exhibited no statistical significance $(p>0.05)$ when other measurements made on the skulls and cadavers were compared. Technique A, a suprazygomatic approach from the midpoint on the lateral border of the orbit, as well as technique $\mathrm{C}$, an infrazygomatic approach with an entry at a point on a vertical line extending along the lateral orbit wall, showed statistical significant differences when measurements of the skulls and cadavers were compared.

On the basis of these findings technique B produces the most consistent data for age groups 1 and 2 and supports the clinical findings recently reported.

Key words: Regional anesthesia; Head and neck nerve blocks; Trigeminal nerve block; Suprazygomatic approach

\section{Background}

Cleft lip and/or palate are considered to be the most frequently encountered craniofacial malformation (1), with a worldwide incidence of approximately 1 in 1000 live births (2-4). Congenital cleft palate repair is ideally performed in the first year of life. The surgery is also considered to be an extremely painful procedure, with the most significant pain experienced in the early postoperative period $(5,6)$.

Regional anesthesia has a number of advantages and can provide postoperative analgesia in infants and neonates, without the risk of respiratory depression (7). Maxillary nerve block within the pterygopalatine fossa can provide sensory blockade of the hard and soft palate (8) and, in this way, provide intraoperative and postoperative analgesia. For the best results, the maxillary nerve needs to be blocked prior to the division of the greater palatine nerve at the location of the foramen rotundum or within the pterygopalatine fossa. The nerve is shielded by the anterior border of the lateral pterygoid plate, superiorly and laterally, as it exits from this foramen (9). The optimal location for a maxillary nerve block is therefore within the pterygopalatine fossa. 
A maxillary nerve block can be considered efficient, simple and safe and improves patient comfort and postoperative analgesia according to Mesnil and co-workers (10). Although several techniques to block the maxillary nerve have been described (10-12), this is the first study to evaluate this block in pediatric cadavers, according to the authors.

This study evaluates the anatomy of three different approaches to the maxillary nerve block in neonatal and infant cadavers with the aim of establishing the most effective method of blocking the maxillary nerve within the pterygopalatine fossa in this age group.

\section{Methods}

Three approaches to the maxillary nerve block were chosen based on a review of the literature. The following criteria were used to select the three techniques:

- newly developed (technique $\mathrm{A}$, has not been evaluated yet)

- most commonly performed (technique $B$ is the most described method in the literature)

- easily comparable (technique $C$ is performed in the same plane and therefore easy to compare to technique $\mathrm{A}$ and $\mathrm{B}$ ).

These techniques were then simulated on 10 dried pediatric skulls and 30 formalin fixed dissected pediatric cadavers within the Department of Anatomy, University of Pretoria, South Africa and conducted according to the Declaration of Helsinki. All cadavers and skulls were legally obtained (according to the South African National Health Act, Act 61 of 2003) and stored in the Department of Anatomy for research and teaching purposes. Ethical clearance to perform this study on the sample of neonatal cadavers was obtained from the Faculty of Health Sciences Research Ethics Committee of the University of Pretoria.

Needles were inserted into the pterygopalatine fossa using the guidelines set out for the three techniques (as described in the paragraphs prior to figure 2, 3 and 4 respectively). Two of the techniques were suprazygomatic approaches (technique $A$ and technique $B$ ) while technique $C$ was an infrazygomatic approach. The sample was divided into two age groups: Group 1 consisted of 
skulls and cadavers of neonates (0-28 days after birth) and Group 2 consisted of the infant skulls and cadavers from 28 days to one year of age. Seven neonatal skulls and 25 neonatal cadavers were measured in Group 1, while three pediatric skulls and five cadavers were measured in Group 2. All three techniques were simulated on both sides of each skull and cadaver. High quality digital photographs were then taken from a superior, anterior and lateral view and subsequently imported into an image analysis program called UTHSCSA Image Tool Version 3. The needle depth and angles to enter the pterygopalatine fossa were then measured and tabulated. The depth was measured from the zygomatic process of the maxillary bone.

From an anterior view, the plane perpendicular with the median plane was considered to be $0^{\circ}$. If the needle is angled superiorly towards the pterygopalatine fossa, it will be considered as an increase $(+)$ in the angle while any inferior angling of the needle will be a decrease (-) (Fig. 1A). From a superior view, the perpendicular plane was again considered to be $0^{\circ}$ with any anterior deviation seen as an increase (+) and any posterior deviation as a decrease (-) in the angle (Fig.1B).
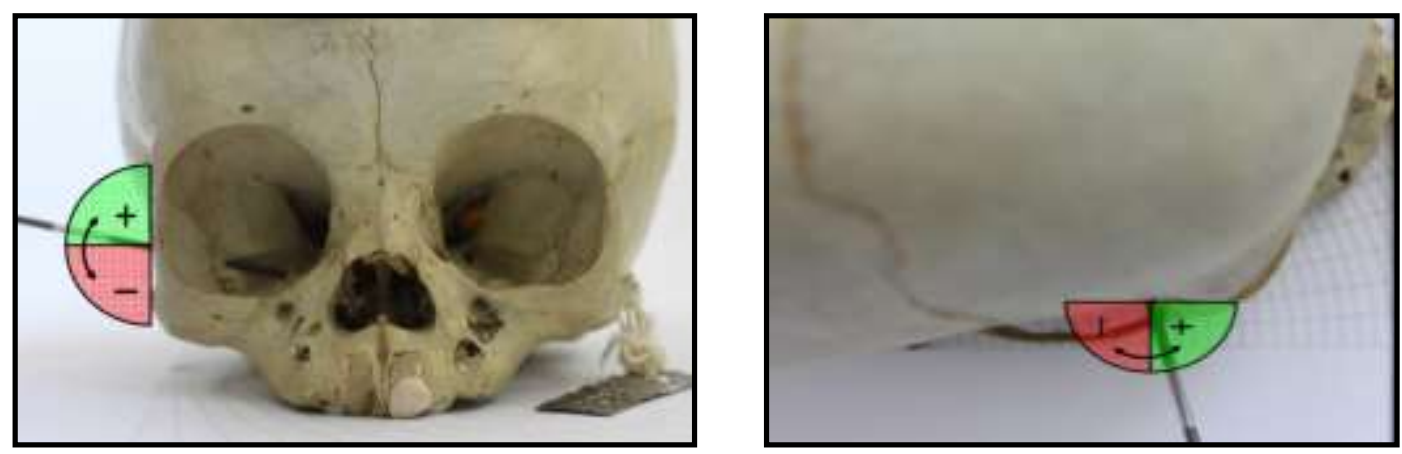

Figure 1: (A) Anterior view and (B) superior views of the pediatric skull indicating the superior / inferior and anterior / posterior angles of the needle, respectively

All measurements for the left and right sides (left vs. right) and the dry skulls and cadavers (skulls vs. cadavers) were compared. The skull measurements were seen as the "ideal" values based on the "visibility" of the pterygopalatine fossa and ease of needle insertion. In contrast, the cadaver measurements were considered to be the "real" values as they more accurately simulated the clinical setting. A technique was considered to be effective if no difference existed between the cadaver ("real") and skull ("ideal") measurements. 
In technique A (Fig. 2A \& B) the needle was placed adjacent to the lateral orbital wall at the midpoint of the orbital opening. The needle was advanced in an inferior direction to reach the pterygopalatine fossa (12).
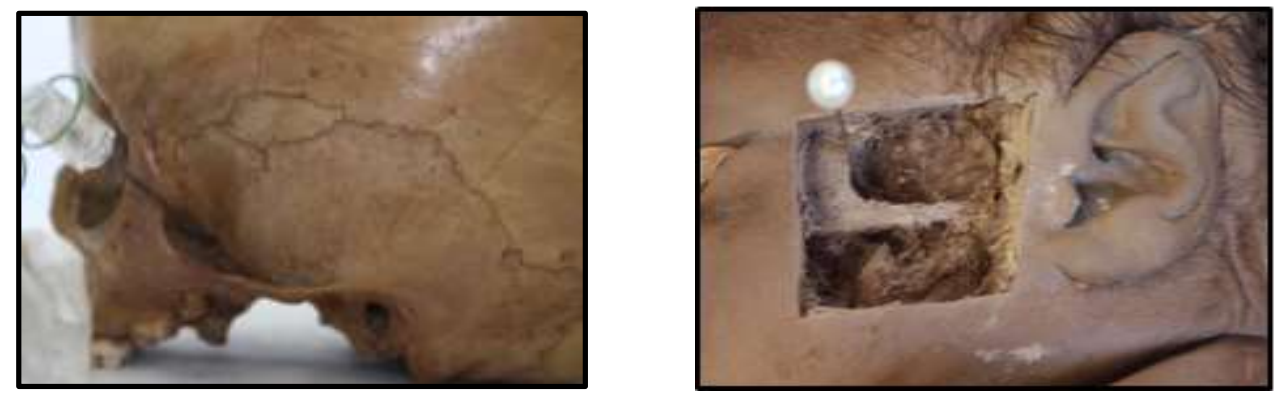

Figure 2: Technique $A$ simulated on $(A)$ a pediatric skull and $(B)$ cadaver

In technique $\mathrm{B}$ (Fig. $3 \mathrm{~A} \& \mathrm{~B}$ ), the needle was placed at the frontozygomatic angle and then advanced medially until the pterygopalatine fossa was reached (10).
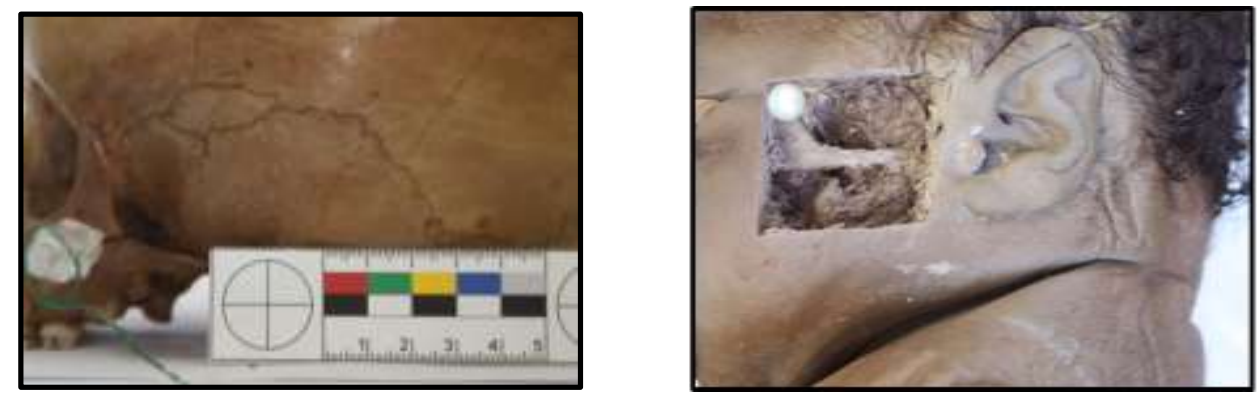

Figure 3: Technique B simulated on (A) a pediatric skull and (B) cadaver

In technique $C$ (Fig. 4A \& B) the needle was inserted through the cheek at a point where a vertical line, extending along the lateral orbital wall, intersected with a horizontal line that ran perpendicular to the lateral aspect of the inferior surface of the zygomatic process of the maxilla (11). 

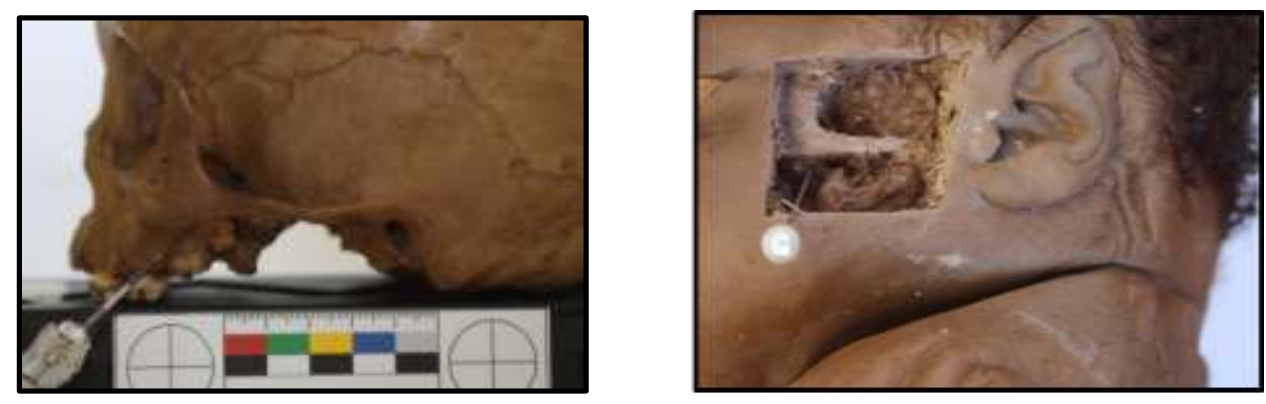

Figure 4: Technique $C$ simulated on $(A)$ a pediatric skull and $(B)$ cadaver

\section{Results}

No statistically significant differences $(p>0.05$; paired t-test) were found between the left and right sides of either the skulls or the cadavers for all three techniques. The sample size for each technique was therefore doubled by the combination of the results, as seen in Table 1.

Table 1: Overall results obtained for pediatric skulls and cadavers, for Group 1 and 2.

\begin{tabular}{|c|c|c|c|c|c|c|c|c|c|c|c|c|c|c|c|c|c|c|}
\hline & \multicolumn{18}{|c|}{ Measurements of pediatric skulls } \\
\hline & \multicolumn{9}{|c|}{ Age group 1} & \multicolumn{9}{|c|}{ Age group 2} \\
\hline & \multicolumn{3}{|c|}{ Technique A } & \multicolumn{3}{|c|}{ Technique B } & \multicolumn{3}{|c|}{ Technique C } & \multicolumn{3}{|c|}{ Technique $\mathrm{A}$} & \multicolumn{3}{|c|}{ Technique B } & \multicolumn{3}{|c|}{ Technique C } \\
\hline & \begin{tabular}{|c|} 
Sup - Inf \\
$\left({ }^{\circ}\right)$
\end{tabular} & $\begin{array}{c}\text { Ant - } \\
\text { Post }\left(^{\circ}\right)\end{array}$ & $\begin{array}{l}\text { Depth } \\
(\mathrm{mm})\end{array}$ & \begin{tabular}{|c|} 
Sup - Inf \\
$\left({ }^{\circ}\right)$
\end{tabular} & $\begin{array}{c}\text { Ant - } \\
\text { Post }\left(^{\circ}\right)\end{array}$ & $\begin{array}{l}\text { Depth } \\
(\mathrm{mm})\end{array}$ & $\begin{array}{c}\text { Sup - Inf } \\
\left(^{\circ}\right)\end{array}$ & $\begin{array}{c}\text { Ant- } \\
\text { Post }\left(^{\circ}\right)\end{array}$ & $\begin{array}{l}\text { Depth } \\
(\mathrm{mm})\end{array}$ & $\begin{array}{c}\text { Sup - Inf } \\
\left(^{\circ}\right)\end{array}$ & $\begin{array}{c}\text { Ant - } \\
\text { Post }\left(^{\circ}\right)\end{array}$ & $\begin{array}{l}\text { Depth } \\
(\mathrm{mm})\end{array}$ & $\begin{array}{c}\text { Sup - Inf } \\
\left({ }^{\circ}\right)\end{array}$ & $\begin{array}{c}\text { Ant- } \\
\text { Post }\left({ }^{\circ}\right)\end{array}$ & $\begin{array}{l}\text { Depth } \\
(\mathrm{mm})\end{array}$ & \begin{tabular}{c|} 
Sup - Inf \\
$\left({ }^{\circ}\right)$
\end{tabular} & $\begin{array}{c}\text { Ant - } \\
\text { Post }\left(^{\circ}\right)\end{array}$ & $\begin{array}{l}\text { Depth } \\
\text { (mm) }\end{array}$ \\
\hline $\mathbf{n}$ & 14 & 14 & 14 & 14 & 14 & 14 & 14 & 14 & 14 & 6 & 6 & 6 & 6 & 6 & 6 & 6 & 6 & 6 \\
\hline Mean & 13.80 & 16.20 & 24.40 & 0.73 & 13.21 & 22.34 & -26.80 & 24.25 & 21.42 & 13.93 & 12.43 & 32.73 & -3.25 & 9.06 & 31.48 & -28.72 & 23.37 & 34.77 \\
\hline SD & 6.33 & 8.50 & 6.11 & 4.83 & 7.74 & 7.04 & 9.05 & 7.99 & 6.70 & 2.28 & 5.48 & 6.14 & 2.38 & 6.15 & 6.48 & 4.62 & 5.20 & 3.66 \\
\hline C195\% & 3.31 & 4.45 & 3.20 & 2.53 & 4.06 & 3.69 & 4.74 & 4.18 & 3.51 & 1.82 & 4.38 & 4.91 & 1.90 & 4.92 & 5.18 & 3.70 & 4.16 & 2.93 \\
\hline Lower & 10.48 & 11.74 & 21.20 & -1.80 & 9.16 & 18.65 & -31.54 & 20.06 & 17.91 & 12.11 & 8.05 & 27.82 & -5.15 & 4.14 & 26.29 & \begin{tabular}{|l|}
-32.42 \\
\end{tabular} & 19.21 & 31.84 \\
\hline Upper & 17.11 & 20.65 & 27.60 & 3.26 & 17.27 & 26.02 & -22.06 & 28.43 & 24.93 & 15.76 & 16.82 & 37.64 & -1.35 & 13.98 & 36.66 & -25.02 & 27.53 & 37.70 \\
\hline
\end{tabular}

\begin{tabular}{|c|c|c|c|c|c|c|c|c|c|c|c|c|c|c|c|c|c|c|}
\hline & \multicolumn{18}{|c|}{ Measurements of pediatric cadavers } \\
\hline & \multicolumn{9}{|c|}{ Age group 1} & \multicolumn{9}{|c|}{ Age group 2} \\
\hline & \multicolumn{3}{|c|}{ Technique $\mathrm{A}$} & \multicolumn{3}{|c|}{ Technique B } & \multicolumn{3}{|c|}{ Technique C } & \multicolumn{3}{|c|}{ Technique $\mathbf{A}$} & \multicolumn{3}{|c|}{ Technique B } & \multicolumn{3}{|c|}{ Technique C } \\
\hline & \begin{tabular}{|c|} 
Sup - Inf \\
$\left({ }^{\circ}\right)$
\end{tabular} & $\begin{array}{c}\text { Ant- } \\
\text { Post }\left({ }^{\circ}\right)\end{array}$ & $\begin{array}{l}\text { Depth } \\
(\mathrm{mm})\end{array}$ & \begin{tabular}{|c|} 
Sup - Inf \\
$\left({ }^{\circ}\right)$
\end{tabular} & $\begin{array}{c}\text { Ant - } \\
\text { Post }\left({ }^{\circ}\right)\end{array}$ & $\begin{array}{l}\text { Depth } \\
(\mathrm{mm})\end{array}$ & $\begin{array}{c}\text { Sup-Inf } \\
\left(^{\circ}\right)\end{array}$ & $\begin{array}{c}\text { Ant- } \\
\text { Post }\left({ }^{\circ}\right)\end{array}$ & $\begin{array}{l}\text { Depth } \\
(\mathrm{mm})\end{array}$ & $\begin{array}{c}\text { Sup-Inf } \\
\left(^{\circ}\right)\end{array}$ & $\begin{array}{c}\text { Ant- } \\
\text { Post }\left({ }^{\circ}\right)\end{array}$ & $\begin{array}{l}\text { Depth } \\
(\mathrm{mm})\end{array}$ & \begin{tabular}{|c|} 
Sup - Inf \\
$\left({ }^{\circ}\right)$
\end{tabular} & $\begin{array}{c}\text { Ant- } \\
\text { Post }\left({ }^{\circ}\right)\end{array}$ & $\begin{array}{l}\text { Depth } \\
(\mathrm{mm})\end{array}$ & \begin{tabular}{|c|} 
Sup - Inf \\
$\left({ }^{\circ}\right)$
\end{tabular} & $\begin{array}{c}\text { Ant- } \\
\text { Post }\left({ }^{\circ}\right)\end{array}$ & $\begin{array}{l}\text { Depth } \\
(\mathrm{mm})\end{array}$ \\
\hline$N$ & 50 & 50 & 50 & 50 & 50 & 50 & 50 & 50 & 50 & 10 & 10 & 10 & 10 & 10 & 10 & 10 & 10 & 10 \\
\hline Mean & 20.03 & 12.13 & 21.60 & 0.07 & 12.91 & 21.10 & \begin{tabular}{|l|}
-32.53 \\
\end{tabular} & 27.04 & 21.33 & 24.97 & 12.13 & 27.74 & 2.50 & 12.06 & 26.74 & -31.17 & 26.53 & 28.55 \\
\hline SD & 5.47 & 5.73 & 3.36 & 6.90 & 4.67 & 3.07 & 9.70 & 9.00 & 3.24 & 8.53 & 4.10 & 3.01 & 6.34 & 6.27 & 4.53 & 6.12 & 5.78 & 2.74 \\
\hline $\mathrm{Cl} 195 \%$ & 1.52 & 1.59 & 0.93 & 1.91 & 1.29 & 0.85 & 2.69 & 2.49 & 0.90 & 5.29 & 2.54 & 1.87 & 3.93 & 3.89 & 2.81 & 3.79 & 3.58 & 1.70 \\
\hline Lower & 18.51 & 10.54 & 20.66 & -1.84 & 11.62 & 20.25 & -35.22 & 24.54 & 20.44 & 19.68 & 9.59 & 25.87 & -1.42 & 8.18 & 23.94 & -34.96 & 22.95 & 26.86 \\
\hline Upper & 21.55 & 13.72 & 22.53 & 1.98 & 14.21 & 21.95 & -29.85 & 29.53 & 22.23 & 30.26 & 14.67 & 29.61 & 6.43 & 15.95 & 29.55 & -27.37 & 30.11 & 30.25 \\
\hline
\end{tabular}

Cl95\%: Confidence Interval of $95 \%$

Lower: Lower range of values with a $95 \%$ confidence level

Upper: Upper range of values with a $95 \%$ confidence level

Negative (-) value with relation to superior - inferior angle indicates that the needle is entered from an inferior angle and proceded superiorly.

The following measurements were obtained for Group 1 on the dried pediatric skulls: For technique $A$, the needle was advanced for $24.40 \mathrm{~mm}$ at a superior angle of $13.80^{\circ}$ and an anterior 
angle of $16.20^{\circ}$; the needle was advanced $22.34 \mathrm{~mm}$ for technique $B$ at an almost horizontal level of $0.73^{\circ}$ and from an anterior direction with an angle of $13.21^{\circ}$. In technique $\mathrm{C}$, the needle had to be inserted at an inferior angle of $26.80^{\circ}$, which meant that the needle was advanced in a superior direction for $24.14 \mathrm{~mm}$ at an anterior angle of $24.25^{\circ}$.

The average distance that the needle was advanced to reach the pterygopalatine fossa in the dried paediatric skulls, in Group 2, for technique A was $32.73 \mathrm{~mm}$. The needle was directed at a superior angle of $13.93^{\circ}$ and from an anterior direction, at an angle of $12.43^{\circ}$. Technique $B$ and $C$ both had a negative angle with regard to the superior-inferior angle. Therefore, in both techniques the needle had to be advanced in an upward direction of $3.25^{\circ}$ and $28.72^{\circ}$ respectively, while the anterior angles were $9.06^{\circ}$ and $23.37^{\circ}$ respectively.

The following measurements were obtained for the Group 1 in the cadaveric specimens. The distance that the needle had to be inserted to reach the pterygopalatine fossa was very similar for the three techniques. These distances were on average, $21.6 \mathrm{~mm}$ for technique $\mathrm{A}, 21.1 \mathrm{~mm}$ for technique $B$ and $21.33 \mathrm{~mm}$ for technique $C$. The anterior-posterior angles for procedure A and B were also similar. Both had to be inserted from an anterior direction at angles of $12.13^{\circ}$ and $12.91^{\circ}$ respectively. Technique $C$ had a much greater anterior angle of $27.04^{\circ}$. The superior-inferior angles differed greatly. These angles were on average at a downward angle of $20.03^{\circ}$, an almost horizontal angle of $0.07^{\circ}$ and an upward angle of $32.53^{\circ}$ for techniques $A, B$ and $C$ respectively

The measurements for the cadavers in Group 2 followed a similar pattern as for those in Group 1. The pterygopalatine fossa was slightly deeper while the distance differed only slightly between technique A $(27.74 \mathrm{~mm})$, technique $B(26.74 \mathrm{~mm})$ and technique $C(28.55 \mathrm{~mm})(p<0.05)$. The anterior-posterior angles for technique $\mathrm{A}$ and $\mathrm{B}$ differed greatly from those of technique $\mathrm{C}$. There was a large variation between the superior-inferior angles that represented the differences in needle direction when progressed into the pterygopalatine fossa. In technique A the needle was advanced at a downward direction, at an angle of $24.97^{\circ}$, while in technique $B$ the needle was inserted almost horizontally at an angle of $2.5^{\circ}$ and in technique $C$ the needle was advanced in a more superior or upward direction at an angle of $31.17^{\circ}$. 
On the basis of the standard deviation and confidence interval analysis, the measurements obtained on both the dry skull and cadaver samples were compared. Technique A exhibited a statistical difference ( $<<0.05$; paired t-test) in both groups 1 and 2 , when comparing the superiorinferior angle of the needle between the values of the skulls and the cadavers, whereas in Technique C a statistical difference $(p<0.05$; paired t-test) was found when the depth to the pterygopalatine fossa in Group 2 was compared between the skulls and the cadavers. Technique B showed no statistical significance in both age groups when comparing the skulls to the cadavers. Consequently, the measurements of the angles and depth to the maxillary nerve at the foramen rotundum within the pterygopalatine fossa were combined, as seen in Table 2.

Table 2: Overall sample for technique B, results from Group 1 and 2 combined

\begin{tabular}{|l|c|c|c|c|c|c|}
\cline { 2 - 7 } \multicolumn{1}{c|}{} & \multicolumn{3}{c|}{ Age group 1 } & \multicolumn{3}{c|}{ Age group 2 } \\
\hline & Sup - Inf $\left({ }^{\circ}\right)$ & Ant - Post $\left(^{\circ}\right)$ & Depth $(\mathbf{m m})$ & Sup - Inf $\left({ }^{\circ}\right)$ & Ant - Post $\left(^{\circ}\right)$ & Depth (mm) \\
\hline $\mathbf{n}$ & 64 & 64 & 64 & 16 & 16 & 16 \\
\hline Mean & 0.21 & 12.98 & 21.37 & 0.35 & 10.94 & 28.52 \\
\hline SD & 6.48 & 5.42 & 4.22 & 5.85 & 6.20 & 5.65 \\
\hline Cl95\% & 1.59 & 1.33 & 1.03 & 2.87 & 3.04 & 2.77 \\
\hline Lower & -1.37 & 11.65 & 20.34 & -2.52 & 7.90 & 25.75 \\
\hline Upper & 1.80 & 14.30 & 22.41 & 3.21 & 13.98 & 31.28 \\
\hline
\end{tabular}

When technique $B$ is used, the needle can be advanced horizontally for approximately $20 \mathrm{~mm}$ in neonatal patients and $30 \mathrm{~mm}$ for patients younger than one year. The needle should be advanced in a posterior direction, by just 'walking' or 'sliding' off the posterior border of the maxilla. The needle should be angled approximately $8-15^{\circ}$, at a point just anterior to the tragus of the contralateral external ear, to reach the pterygopalatine fossa. The following layers will be traversed by the needle towards the pterygopalatine fossa:

- Skin

- Subcutaneous fat and fascia

- Superficial layer of temporalis muscle

- Deep layer of the temporalis muscle including the temporal fat pad located between the layers of the temporalis muscle and 
- Portion of fat pad continuous with the buccal fat pad.

It's important to identify the superficial fat pad, since accidental injection of anesthetic into it may cause fat necrosis (13).

\section{Discussion}

Maxillary nerve blocks are being used for peri-operative analgesia after cleft palate repair in infants. Nerve blocks can dramatically reduce the consumption of opioid for postoperative pain relief (10). However, the best approach for blocking the maxillary nerve in pediatric patients has yet to be established.

Technique A was found to be more difficult to simulate because the bony landmarks were difficult to palpate on the cadavers. This may explain the significant difference in angles in comparing the procedure on the skulls and the cadavers.

The depth to the pterygopalatine fossa using the infrazygomatic approach, technique C, was statistically different in Group 2. This was not surprising since there was more soft tissue to transverse in the cadavers.

The bony landmarks in technique B were more superficial and could be easily palpated. No statistical difference $(p>0.05)$ was observed when comparing the skull and cadaver measurements for either age group.

The results of this study show that technique B is the easiest and most reliable method of blocking the maxillary nerve, which corresponds with several other studies $(10,14,15)$. Stajčić and Todorovic (14) suggest that this technique is the safest approach and endorse this method since this approach reaches only the anterior part of the pterygopalatine fossa, which will prevent the needle from passing into the infra-orbital fissure and potentially damaging the infra-orbital contents. 
Mesnil and co-workers (10) evaluated the effectiveness of a bilateral suprazygomatic maxillary nerve block. The needle was inserted perpendicular to the skin, and advanced approximately $20 \mathrm{~mm}$ to reach the greater wing of the sphenoid. The needle was then redirected and advanced $35 \mathrm{~mm}-$ $45 \mathrm{~mm}$ at a $20^{\circ}$ anterior and $10^{\circ}$ caudal direction toward the philtrum, to reach the pterygopalatine fossa. In this study the distance was measured from the level of the skin, unlike our study that measured from the frontozygomatic angle.

In comparison Captier and co-workers (15) studied computed tomographic (CT) scans of 55 infants to determine the distance and trajectory of a needle from the frontozygomatic angle to the greater wing of the sphenoid bone. The distance measured was $24.1 \mathrm{~mm} \pm 2.7 \mathrm{~mm}$ with a trajectory of $19.3^{\circ} \pm 5.3^{\circ}$ in a forward direction. These measurements are similar to those obtained in our study although there was slight variance when comparing the angles, that can be attributed to the different measuring techniques used.

A limitation of this study was the exclusion of skin tissue depth since the cadaver measurements were taken from the level of the zygomatic arch after removal of the skin during dissection. However, this bony landmark is very superficial and is easily palpated. This depth is clinically negligible and the needle can be inserted using the depth obtained from this study as a guideline.

This technique needs to be tested in a clinical setting to ensure that the measurements in terms of the angles and depths at which the needle needs to be introduced to reach the pterygopalatine fossa is sufficiently accurate in order that a successful maxillary nerve block in infants can be achieved.

In conclusion, the suprazygomatic approach from the frontozygomatic angle (technique B) produces the most consistent results in pediatric cadavers. Using this approach, the needle can be advanced horizontally for approximately $20 \mathrm{~mm}$ in neonates and $30 \mathrm{~mm}$ for infants younger than one year. The needle should be advanced in a posterior direction, towards a point just anterior to the tragus of the contralateral external ear (this should be approximately between $8^{\circ}$ and $15^{\circ}$ ) to reach the 
pterygopalatine fossa. The needle can be guided into the fossa by 'walking' off the posterior aspect of the maxilla.

\section{Ethical approval}

Ethical approval to conduct dissections on a sample of neonatal cadavers within the Department of Anatomy, University of Pretoria, was obtained from the Faculty of Health Sciences Research Ethics Committee of the University of Pretoria (S128/2010). All dissections were conducted in the Department of Anatomy under the rules and regulations stipulated in the South African National Health Act, Act 61 of 2003.

\section{Conflict of interests}

None of the authors has any conflicts of interest to declare.

\section{Financial assistance}

The financial assistance of the National Research Foundation (NRF) towards this research is hereby acknowledged. Opinions expressed and conclusions arrived at are those of the authors and are not necessarily attributed to the NRF.

\section{Acknowledgements}

The authors of this article would like to thank Ms. B English, research consult from the Faculty of Health Sciences, University of Pretoria for her valued assistance. 


\section{References}

1. Haberg C, Larson O, Milerad J. Incidence of cleft lip and palate and risks of additional malformations. Cleft Palate Craniofac. J 1998; 35: 40-45.

2. Thaller SR, Mele J, Hoyt J. The effect of antenatal surgery of craniofacial growth in a sheep model. Plast Reconstr Surg 1995; 96: 1-8.

3. Strong EB, Buckmiller LM. Management of the cleft palate. Facial Plast Surg Clin North Am 2001; 9: 15-25.

4. Moore KL, Persaud TVN, Torchia MG. The developing human: Clinically oriented embryology. $9^{\text {th }}$ edition. Saunders Elsevier, Philadelphia, 2011.

5. Doyle E, Hudson I. Anaesthesia for primary repair of cleft lip and cleft palate: a review of 244 procedures. Paediatr Anaesth 1992; 2: 139-145.

6. Obayah GM, Refaie A, Aboushanab $\mathrm{O}$ et al. Addition of dexmedetomidine to bupivacaine for greater palatine nerve block prolongs postoperative analgesia after cleft palate repair. Eur $J$ Anaesthesiol 2010; 27: 280-284.

7. Welborn LG, Ramirez N, Oh TH et al. Postanesthetic Apnea and Periodic Breathing in Infants. Anaesth 1986; 65: 658-661.

8. Rochette A, Dadure $\mathrm{C}$, Raux $\mathrm{O}$ et al. Changing trends in paediatric regional anaesthetic practice in recent years. Curr Opin Anaesthesiol 2009; 22: 374-377.

9. Singh B, Srivastava SK, Dang R. Anatomic considerations in relation to the maxillary nerve block. Reg Anaesth 2001; 26: 502-511.

10. Mesnil M, Dadure C, Captier G et al. A new approach for peri-operative analgesia of cleft palate repair in infants: the bilateral suprazygomatic maxillary nerve block. Pediatric Anesthesia 2010; 20: 343-349.

11. Stechison MT, Brogan M. Transfacial transpterygomaxillary access to foramen rotundum, sphenopalatine ganglion, and the maxillary nerve in the management of atypical facial pain. Skull Base Surgery 1994; 4: 15-20.

12. Du Plessis M. Comparative study of the pterygopalatine fossa and its ganglion. MSc, University of Pretoria, 2010.

13. Zuckerman JD, Meislin RJ, Rothberg M. Injections for joint and soft tissue disorders, when and how to use them. Geriatrics. 1990; 45: 45-52. 
14. Stajčić Z, Todorović L. Blocks of the foramen rotundum and the oval foramen: a reappraisal of extraoral maxillary and mandibular nerve injections. Br J Oral Maxillo-fac Surg 1997; 35: 328333.

15. Captier G, Dadure C, Leboucq N et al. Anatomic study using three-dimensional computed tomographic scan measurement for truncal maxillary nerve blocks via the suprazygomatic route in infants. J Craniofac Surg 2009; 20: 224-228. 